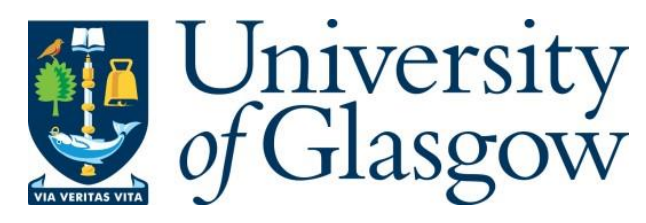

Pickering, L. and Moffat, N. (2019) 'Out of Order': the double burden of menstrual etiquette and the subtle exclusion of women from public space in Scotland. Sociological Review, 67(4), pp. 766-787. (doi:10.1177/0038026119854253)

There may be differences between this version and the published version. You are advised to consult the publisher's version if you wish to cite from it.

\title{
http://eprints.gla.ac.uk/189561/
}

Deposited on: 3 July 2019

Enlighten - Research publications by members of the University of Glasgow http://eprints.gla.ac.uk 


\section{'Out of Order': The double burden of menstrual etiquette and the subtle exclusion of women from public space in Scotland}

\section{Natalie Moffat and Lucy Pickering}

nataliemoffat95@gmail.com

\section{$\underline{\text { Abstract }}$}

This chapter examines the double burden of 'menstrual etiquette' and their implications for women's inclusion in public spaces in Scotland today. Beginning from Laws' work on 'menstrual etiquette' (Laws, 1990), we explore how menstrual etiquette is characterised primarily by the burden of rendering menstruation invisible, both discursively and practically. However, women not only work to ensure that others remain unaware that they are menstruating; they depend on technologies, such as menstrual product dispensers and bins, to facilitate this process of rendering menstruation invisible. When these technologies are absent or poorly maintained, women experience a double burden: not only must they maintain the social invisibility of menstruation but do so without social or infrastructural support or drawing attention to this absence (for fear of breaching the discursive silence demanded of menstrual etiquette). We locate poor maintenance of facilities with in the very same 'civilising process' (Elias, 1978) that has pushed women's bodily management to the furthest reaches of the private sphere. Socially invisible, these infrastructural supports are granted low status and poorly maintained. The pressure to maintain conceptual silence around menstruation limits women's capacity to contest this neglect and, in turn, perpetuates their exclusion from public space. This paper, then, exposes the nature and the compounding temporal and affective burden of menstrual etiquette and advocates for breaking discursive silences to facilitate much needed social change.

Keywords: Menstruation, Menstrual Etiquette, Shame, Gender, Scotland 


\section{'Out of Order': The double burden of menstrual etiquette and the subtle exclusion of women from public space in Scotland}

\section{$\underline{\text { Introduction }}$}

Menstruation is both a biological and a cultural event (Kissling, 1996); however, it is one which is only experienced by female-sexed bodies. As such, how menstruation is understood and rendered socially acceptable can be deeply revealing of wider ideas about gender, propriety and public space. This chapter draws on Laws' concept of menstrual etiquette (Laws, 1990) to empirically explore how acceptable menstrual practice is learned, enacted and increasingly resisted among a cohort of female students from a Scottish University.

We argue that menstruation is a historically overlooked dimension of social life, and thus of social research, and that this lacuna is itself a product of a number of convergent forces, in particular the Cartesian split and the 'civilising process' detailed by Elias (1978). Through exposing the analytical silence and the hard work required of menstruating women to maintain the conceptual silence required by menstrual etiquette, we argue for a new menstrual etiquette - one which actively acknowledges and works to undermine the 'double burden' of social and infrastructural invisibility.

\section{Unpacking Menstrual Etiquette}

Laws (1990) argues that in secular British culture, menstruation is best understood through the frame of 'menstrual etiquette', an intricate set of rules centred around the premise that all evidence of menstruation must be hidden. This entails a lot of work: women must conceal both blood and the products used for this concealment whilst ensuring menstruation is not mentioned. These practices are, for Laws, both a product and reinforcement of gender hierarchies.

Longhurst (2001), in turn, has drawn attention to the affective dimensions of menstruation and the feelings of discomfort and shame associated with the 'leakiness' of women's bodies. We argue that these factors - shame, masking from social view and its highly gendered nature - are the culmination of a number of historical forces; forces which have shaped both the drive towards and current forms of 'menstrual etiquette' while simultaneously containing the seeds of its own (potential) undoing. These forces include the 'civilising process', mind-body and public-private dualisms, and self-governance.

To understand menstrual etiquette in Scotland, we must first examine how bodily excretions have come to be regarded as shameful and requiring of privatisation. Through tracing developments in manners and etiquette in Western Europe from the Middle Ages onwards, Elias (1978) details a set of social transitions which include a shift from managing bodily excretions in public to an increasing expectation that they be managed privately. These shifts in bodily practice co-occurred with changes in how power was competed for 
(through 'courtly intrigues' rather than physical battles), the management of emotion, and bodily presentation and comportment in general - gradually bodily functions came to be regarded as 'distasteful' and something to be 'removed behind the scenes of social life' (van Krieken, 1998, p.96). According to Elias, heightened self-awareness emerged in tandem with heightened self-discipline, leading to feelings of shame if bodily processes were not concealed from social view ${ }^{1}$. There was an increased expectation to keep so-called 'natural functions' "hidden away in back-regions" (Shilling 2003, p. 136). These behavioural codes, developed over centuries, are now swiftly instilled in children through parent-led toilet training and peer-led shaming in the space of the semi-public primary school toilet (Lea 2001; Shilling 2003).

This civilising process can be read as classed, whereby elites (based on privileged access to necessary material resources) use evolving hygiene norms as a site of distinction (Inglis 2001; Stallybrass \& White 1986). Today, Scotland has the material and social infrastructure to facilitate access to clean water and flush toilets for almost all citizens ${ }^{2}$. As a result, this site of classed distinction has dissolved into a shared set of largely invisible norms. However, attending only to this process of dissolution risks overlooking the highly gendered ways in which the 'civilising process' has played out.

Central to the European Enlightenment of the $18^{\text {th }}$ century was the Cartesian dualism, separating 'mind' from 'body.' For feminists such as Bordo (1995), Grosz (1994) and Shildrick and Price (1999), this carries significant gendered implications. The capacity to reason was hailed as the defining characteristic of personhood (Bordo, 1995) and, with reason being located in the mind, the body became reduced to, at best, a vessel and, at worst, the opposite to rational thought (Grosz, 1994; Shildrick \& Price, 1999). Both male and female bodies secrete fluids; however, while leakiness came to be increasingly devalued in male bodies (Smith, 2011) the reproductive processes unique to females were selectively focused on to inscribe their bodies as a 'mode of seepage' (Grosz, 1994, p. 203). This emphasised their otherness to men and located women firmly on the side of the body (see also Longhurst, 2001), leading to a gendered binary of solidity, rationality and masculinity and fluidity, irrationality and femininity (Irigaray, 1985).

Grosz (1994, p. 195), drawing upon Douglas' (1966) work on dirt and Kristeva's (1982) conceptualisation of the abject, argues that different bodily fluids have 'different indices of control, disgust and revulsion.' According to Sartre, a viscous fluid 'repels in its own right', with its stickiness not only blurring the boundary between solid and liquid but attacking the very distinction between experiencing self and experienced environment (Sartre, 1943, cited in Douglas, 1966, p. 39). This is seen by Douglas as threatening all efforts to categorise the world and create order (Douglas, 1966). Menstrual blood is a viscous fluid that does not dry invisibly and flows uncontrollably and, thus, emerged as a pre-eminent symbol of sex

\footnotetext{
${ }^{1}$ While we focus on menstruation, this process has been examined in detail in relation to defecation (Inglis, 2001) and can be linked to the ways in which apparent failures of bodily control impact negatively on contemporary perceptions of personhood, especially among already marginalised groups (Lea, 2001; Paterson \& Hughes, 1999; Pickering, Neale \& Nettleston, 2013).

${ }^{2}$ Recent closures of public toilets have reduced options of homeless people to access excretory spaces, particularly outside the opening hours of the so-called 'publicly accessible toilets' of libraries, community centres and so on (Edinburgh City Council, 2017).
} 
difference, appearing to conform to and confirm male/female, rigid/fluid binaries. Thus, while Elias (1978) traced a separation of public and private as a consequence and driving feature of the 'civilising process' more generally, some feminist scholars read this in strongly gendered terms, noting the linkage of those practices associated with the "back-regions" and the private sphere with female bodies, and public action and public space with 'boundaried' male bodies. This distinction served not only to exclude women from public space and public discourse (Beard, 2017) but also those men who cannot conform to the rigid, boundaried male bodily ideal (see, for example, Paterson \& Hughes, 1999, on disability, the bounded body and exclusion).

However, since the latter half of the 20th century, women have increasingly participated in public institutions (Young, 2005), bringing their 'leaky' bodies with them. Yet this has not resulted in a correlative shift in attitudes towards menstruation: the management of menstruation has remained a highly personal, private act which needs to be concealed at all costs. Menstruation can, then, be seen as 'matter out of place' (Douglas 1966, p. 36): not only as something historically privatised but as actively polluting and, as such, requiring suppression in order to maintain 'cherished classifications' $(1966$, p. 37). Not only does (menstrual) blood become 'matter out of place' as it transgresses bodily boundaries, but it as with all forms of pollution - threatens the social order by its very existence. In British society, this history of patriarchy and the 'civilising process' has justified women's restriction to the private sphere on the grounds of their 'leaky' bodies. Now that women actively engage in public life, the public appearance of menstruation, as an inherently female bodily fluid, symbolises the threat to these boundaries. ${ }^{3}$

Menstrual etiquette reinforces the notion that bodies that belong in public (imaginatively at least) possess solid boundaries. Women must, therefore, work to mask the 'leakiness' of their bodies (Longhurst, 2001) in order to gain acceptance within the public sphere. Leder's concept of 'dys-appearance' offers a framework for thinking about this work. He argues that the normally conceptually 'absent body' only enters consciousness during periods of dysfunction; in these moments of dys-function it 'dys-appears'. But dys-appearance is social as well as phenomenological, with 'social dys-appearance' referring to the conscious awareness of the body due to the 'incorporated gaze of the Other' (1990, p. 96). The body, as we shall see, dys-appears during menstruation - both phenomenologically and socially.

Social dys-appearance, and the subsequent enactment of menstrual etiquette, can be read as an expression of Foucault's notion of 'governance' (Foucault, 1977). Foucault's theory of power rests on the idea that from the 18th century onwards, the exercise of power shifted from overt violence to surveillance and, in particular, self-surveillance whereby individuals internalise the views of the powerful and assume sole responsibility for self-regulating and conforming to them. This insight is central to the work of many feminist scholars, such as Bordo (1995), who argues that with the growth of capitalism in Western societies around

\footnotetext{
${ }^{3}$ Beliefs and practices regarding menstruation must be interpreted within the cultural context of their enactment and we focus on Western treatment of menstruation. See Buckley and Gottlieb (1988) for alternative constructions cross-culturally of menstrual blood as 'polluting', sometimes indicating the power of women in positive, as well as destructive, ways.
} 
the nineteenth century, bodily control came to symbolise success. However, since throughout Western intellectual thought 'the capacity for self-management is decisively coded as male [whilst] all those bodily spontaneities... seen as needful of containment and control have been culturally constructed and coded as female' (Bordo, 1995, p. 206), women have been deemed incapable of achieving sufficient self-control. Menstruation has been seen to mark their out-of-control status in relation to the male ideal; thus, to engage in the public sphere, and be afforded the same rights and privileges as men, women face pressure to manage and privatise menstruation (Young, 2005). The effect of menstrual etiquette (as with any disciplinary power) is that prevailing structures of dominance and subordination (in this case, the gendered 'public-private' binary) are sustained 'from below' through the self-regulatory actions of subordinated people themselves (Bordo, 1995, p. 27). These themes recur in the body of empirical research into menstrual etiquette which has recently begun to emerge.

\section{$\underline{\text { Menstrual Etiquette in Practice }}$}

Gendered dimensions of Elias' civilising process reveal themselves in several ways in empirical research into menstruation. Firstly, studies predominantly show that women consider menstruation an intimate process to be hidden. Jackson and Falmagne (2013) highlight that maintaining secrecy is a primary concern of girls in the USA upon menarche, resulting in heightened bodily shame, and Brantelid, Nilver and Alehagen (2014) demonstrate that, in Sweden, this belief continues into adulthood.

Furthermore, menstruation must be discursively, as well as practically, hidden. JohnstonRobeldo and Chrisler (2013) explore how this is done through the employment of euphemisms and how except in intimate relationships, such as with close female friends and relatives, menstruation is typically avoided in conversation, especially around males. In the Tampax Report, conducted in the USA, most adults surveyed believed that menstruation should not be mentioned in 'mixed company' (Research \& Forecasts, 1981) and Williams (1983) found that $85 \%$ of adolescent girls in the USA surveyed believed menstruation should not be discussed with boys and $33 \%$ would not talk about it with their fathers. More recently, Newton (2016, p. 105) found that in England 'menstruation was still viewed as something which should only be kept between daughters, mothers and sisters.'

It appears, then, that a central tenet of menstrual etiquette is that men must not know (Laws, 1990). The 'social imperative not to offend' them with knowledge of menstruation may become 'binding' (van Krieken, 1998, p. 96) through the menstrual education girls receive. Observing a high school 'Puberty Day', Newton (2012) notes the gender divide, when a school nurse teaches only female students about menstruation, indicating it is a topic for women alone. Preceding this, girls often receive information from their mothers but as Kissling outlines, this is usually done in what is referred to as 'the talk' - an occasion, often described as embarrassing, where a mother takes her daughter aside to explain female bodily changes during puberty, also promoting the idea that menstruation is a secret 'female issue' (Kissling, 1996, p. 495). 
Something which appears to underpin the need to conceal menstruation is the appraisal of menstrual blood as "dirty" (Martin, 1989) and "gross" (Brantelid et al., 2014). The 'feminine hygiene' industry capitalises on this, marketing menstruation as a 'hygienic crisis' that can only be managed effectively by using their products to feel 'fresh' and 'confident' by avoid soiling, odour and embarrassment (Jackson \& Falmagne, 2013; Johnston-Robeldo \& Chrisler, 2013; Newton, 2012). Notions of cleanliness have also been shown to influence women's choice of menstrual products. Women in the USA have expressed revulsion at the blood on sanitary towels, often preferring tampons (Martin, 1989), and Oxley's UK survey on menstrual management uncovered similar perceptions, with one woman specifically stating that she felt cleaner when using tampons as "your period doesn't leave your vagina" (1998, p. 188).

As touched upon previously, reactions of disgust towards menstruation can lead to women in Western societies feeling anxious about their menstruating status being revealed especially in public. Numerous studies report that women feel self-conscious during menstruation, with fear of visibly 'leaking' a central concern (Brantelid et al., 2014; Ginsburg, 1996; Jackson \& Falmagne, 2013; Kissling, 1996; Martin, 1989; Oxley, 1998). Stress about being unable to dispose of used menstrual products in specialist bins has also been highlighted (Brantelid et al., 2014; Jackson \& Falmagne, 2013) and, even before use, women feel a need to carry these products secretly Burrows \& Johnson, 2005; Jackson \& Falmagne, 2013; Kissling, 1996). These findings indicate the internalisation of a pollution belief.

Women understand their menstrual blood to be something "gross" and shameful that needs to be hidden from public view and managed privately. It is not only 'matter out of place' as it transgresses bodily boundaries, but, we argue, its visible presence also potentially marks women's bodies as out of place in public spaces. As a result, women work to enact menstrual etiquette: successfully doing so is made especially challenging in settings where menstruation (and, thus, the infrastructure required to facilitate its management) is socially disappeared and so not considered in design (Greed, 2016).

Women are expected to quietly manage menstruation, with some stating that it is unacceptable to let it affect their daily lives (Brantelid et al., 2014). However, it proves difficult to meet the needs created by the intersection of bodily processes and public institutions which assume a 'standard' non-menstruating body. Women must find ways to either clean or change, dispose of, and acquire menstrual products efficiently and without detection in spaces which often fail to provide the necessary time, space and equipment for them to do so effectively (Young, 2005). For example, high school girls in the UK noted that menstrual product dispensers in female toilets were broken, making it difficult to obtain these items when needed (Burrows \& Johnson, 2005). The numerous practical difficulties encountered when menstruating outside the home can make menstrual management a "hassle", contributing to negative attitudes towards the process (Choi \& McKeown, 1997; Martin, 1989).

Due to the concealment norms of menstrual etiquette and disregard of menstruation in public spaces, women face a double burden to ensure their menstruation remains privatised. In terms of avoiding leaking, one girl in Burrow and Johnson's sample admitted to 
wearing a pad all the time "just in case" (2005, p. 239). Work is also required to discretely carry and use menstrual products. Martin (1989) notes that in school girls often sneak menstrual products up their sleeves, in socks or inside notebooks, and Ginsburg (1996) highlights that pockets and bags are used to carry menstrual products surreptitiously.

In addition to the practical difficulties involved with managing menstrual blood in public spaces, many women also contend with menstrual pain. Oxley (1998) revealed various strategies to manage this, such as wearing comfortable clothing and taking painkillers, and Young (2005) argues that these become required when schools and workplaces remain insensitive to pain during menstruation, symptomatic of the wider neglect of issues surrounding menstruation in the public sphere.

Finally, the imperative to manage one's menstruating body is shown in its most extreme form through women's use of contraceptives to exert full control over, or even eradicate, the process (Granzow, 2007; Johnston-Robeldo, Ball, Lauta \& Zekall, 2008; Kissling, 2013; Mamo \& Fosket, 2009). Women in Canada, interviewed by Granzow (2007) about their use of oral contraceptives, described taking them in order to have more control over their lives, through predicting the exact timing of their menstruation and having the 'choice' to suppress the process at times where it would be inconvenient. It appears, then, that women in a range of Western societies experience an obligation to self-regulate to ensure that menstruation does not present itself in public spaces and remains a private, individual issue.

The limited nature of this overview of empirical research into menstruation highlights the marginalised status of menstruation as a topic of scholarly enquiry. However, consistent themes do emerge in this body of work: menstrual etiquette focuses on maintaining the social disappearance of menstruation and influences the behaviour of menstruating women in a range of Western societies; women's internalisation of these pressures to render menstruation invisible drive these behaviours and are linked to feelings of shame about the process. At the same time, menstrual etiquette depends on material infrastructure and this is not always maintained. As a result, women face a double burden: they need to maintain the hiddenness of menstruation while the infrastructure required for them to do this is neglected, itself a product of the social invisibility of menstruation. The rules of menstrual etiquette and this infrastructural neglect combine into a form of 'subtle sexism' (Moore, 2002): i.e. something that often goes unnoticed and is considered natural, normal or acceptable but serves to maintain women's lower status. This chapter seeks to explore these themes in relation to women in Scotland.

\section{Methods}

This research began from three interlocking premises: that gender is a fundamental organising principle of Western social life, that the nature of this is 'unequal and hierarchical' (Skeggs, 1994, p. 77), and that 'the personal is political' (Letherby, 2003, p. 4). This research, then, is shaped profoundly by feminist scholarship: it focuses on an aspect of social life often pushed to the margins and sought to understand women's experiences of this through group discussion. Focus groups allow the collection of data on group norms and 
encourage participants to develop their views from hearing the perspectives of others (Kitzinger, 1994) as well as being highly compatible with the ethics and politics of feminism, where researchers shift expertise and a high level of control over the content and direction of the discussion to participants (Bryman, 2012).

However, it has been questioned whether focus groups are suitable for so-called sensitive topics (Madriz, 2000). Which raises the question, is menstrual etiquette a sensitive topic? It is one that women do not often talk about, much less with non-intimate others, as noted by Lily (all participants are referred to by pseudonyms):

"Before this focus group I was a bit like, $\mathrm{mm}$, I probably won't speak much because it's quite, like, a personal subject."

However, this constraint, we argue, is itself a product of menstrual etiquette and the social pressures to disappear menstruation from social view (including discourse) and not an effect of an inherent 'sensitivity'. Further, Madriz has advocated the discussion of 'taboo' subjects, such as menstrual etiquette, through methods where experiences and feelings are likely to be shared as they provide the relatively rare opportunity for women to 'empower themselves by making sense of their experience of vulnerability and subjugation' (2000, p. 843).

Kitzinger (1994) and Letherby (2003) have also argued that focus groups facilitate the expression of intimate experiences, as shyer participants can become more comfortable to disclose after less inhibited group members 'break the ice', and co-participants can support one another. This sense of support emerged in how some participants reflected on the experience:

"Discussing menstruation in situations like this is good for women... That's quite empowering... we should be able to talk about it and it's encouraging that we can in certain situations" (Jasmine).

'Women over the age of 18 with experience of menstruation' (as it was worded in recruitment materials) were recruited from the student body at a Scottish university. To the best of our knowledge, all were cisgender. Eighteen women, aged 19-32 (mean 21.6) participated in three focus group discussions in September and October, 2016. Engagement with the topic was active, and focus groups lasted on average for 1 hour and 45 minutes.

Focus group discussions were transcribed verbatim and analysed using thematic analysis. In line with the commitment to de-centre the supposed expertise of the researcher, data was coded using open coding and indexed to highlight information potentially of interest (Seale, 1999). These initial labels were then refined, with recurring conceptual patterns emerging across focus groups subsequently developed into overarching themes.

This project received ethical approval from the University of Glasgow School of Social and Political Sciences Ethics Forum. Given the potential for this topic to be seen as 'sensitive', the emphasis on discussing experiences of and feelings about menstruation was made clear in recruitment materials and addressed again verbally at the start of each focus group discussion. 


\section{$\underline{\text { Menstrual Etiquette in Scotland }}$}

Over the course of the focus group discussions it became clear that menstruation was viewed as something to hide, both practically and discursively. The nature of participants' menstrual education also seemed to instil a belief that female bodies are especially problematic and men must be protected from exposure to menstruation.

Consistent with a civilising process framework and in line with previous research (e.g. Brantelid et al., 2014; Jackson \& Falmagne, 2013), participants recounted knowing menstruation should be privatised from early on. As Louisa and Katie stated:

"I think people just kind of... like to keep it hidden and that's something you're kind of brought up with."

"I subconsciously knew I had to keep it a secret."

This sense of secrecy also shaped how women talked about menstruation. Consistent with Johnston-Robeldo and Chrisler (2013), Jasmine explained, "I would never use the word "menstruation'", and euphemisms such as "Mother Nature", "shark week" and "time of the month" (even further masked with the acronym "Tom") were described:

"That's what we used in school. Like, 'Tom's come to stay'... and the others would be like, 'Ah, are you ok?'” (Megan).

Most participants explained that these euphemisms were most often employed when they were younger and now they usually referred to their 'period', although, as Jasmine noted above, 'menstruation' was not a popular term and used only rarely, even in these focus group discussions.

Reading these euphemisms through an Eliasian lens, they operate to disappear menstruation, with its connotations of bloodiness and bodiliness, from discourse. They also enable women and girls to articulate to one another an important state without risking exposure to outsiders (i.e. men). But with this masking comes shame: not only is this something hidden, but it is something that ought to be hidden. And it was apparent in participants' discussion of their menstrual education that menstruation as a female bodily function appeared to be particularly shameful, and especially requiring of privatisation.

Reflecting Kissling's (1996) findings, participants described "the talk" as a one-on-one discussion with their mothers, set apart from ordinary dialogue:

"She was kinda like, 'Sit down. We need to talk about something', and I was like, 'Oh my god, I'm in trouble'" (Katie).

This experience was clearly not regarded positively, but something they felt was "such a big deal" (Francesca), "awkward" and "embarrassing" (Ruby). Learning about menstruation in this way marked it as a private matter that should only concern females, a gendering mirrored in school-based menstrual education. Consistent with Newton (2012), lessons 
about menstruation were solely a "girl's issue" (Megan). Indeed, Nina remembered being explicitly told not to concern males about menstruation:

"In primary school... we had a special lady come in to tell us about periods and the girls and boys got separated [...] and then she was like, 'Don't bother your dads about this because they won't want to hear [...] it's something to talk to your mum about."'

This secrecy surrounding menstruation, however, was not paralleled for male-specific leakages:

“We'd learn about wet dreams as a class but the boys weren't allowed to learn about periods" (Nina).

"We had to sit and talk about the fact that we're gonna get periods... and the boys didn't have that so the boys had absolutely no idea what was going on inside the woman's body and then you [...] had the sex talk and it was discussed at length what happened in the man's body" (Tess).

The effect of this sequestering of female bodily change at puberty in contrast to male was that:

"You were almost made to feel... when you had the girl's talk like there was something wrong with you" (Caitlin).

As Elias (1978) argued, the civilising process required that bodies' natural functions became increasingly 'hidden away in back-regions' to avoid shame and facilitate acceptance as a civilised member of society (Shilling, 2003, p.136). However, this gendering of puberty education in schools led to at least some of the women discussed here learning that female bodies are particularly problematic, particularly demanding of masking and, consequently, a greater source of shame than their male counterparts (Grosz, 1994). Further, as already noted above, girls were encouraged from early on to protect males from any exposure to menstruation. When discussing her experience of menarche, Louisa explained:

"My mum used to keep the box with all the pharmaceutical stuff in her room with, like, my dad... I remember I went through... and I was so stressed... I said to her, '[...] You cannot say to dad [...], pretend you're getting something else'”.

This need to conceal menstruation from men also pervaded participants' current experiences (see also Newton, 2016; Research \& Forecasts, 1981; Williams, 1983):

Megan: "I think I still wouldn't talk to my dad about it"

Ruby: "Yeah, same. My dad or my brother. Not a chance."

This drive to protect men from exposure to menstruation enhanced stress during the necessary process of buying products to manage menstruation: 
"I used to hate going to the shop to buy sanitary towels ${ }^{4} . .$. it was the guys at the till and the guys in the shop and I didn't want to, you know, have them out" (Anna).

"If self-check-out's not available l'll stand there being like, 'Not a guy, not a guy"” (Ruby).

It appears, therefore, that the 'social imperative not to offend' men with knowledge of menstruation is 'binding'; women carry a heavier burden in terms of 'distasteful' bodily functions that are to be 'removed behind the scenes of social life' (van Krieken, 1998, p. 96) due to understandings of their bodies as 'leaky' and unpredictable compared to the apparently solid boundaries of male corporeality (Longhurst, 2001).

This removal requires work; already noted is the management of shame and embarrassment when faced with having to buy menstrual products from men but women also face additional difficulties concealing menstruation in the public sphere due to infrastructural and attitudinal non-acceptance. A key issue for these women was the inclusion - but not maintenance - of menstrual product dispensers located in public settings such as university libraries:

"I went to every single bathroom [...] and not one [dispenser] produced a tampon. So, I had to leave the university... walk all the way to Tesco's [...] I was so, like, angry that I almost felt like writing a letter to the university... but then I almost just felt, like, not ashamed but like nobody would care about tampons" (Eliza).

When menstrual product dispensers are 'out of order', women bear the menstrual etiquette burden of stopping what they are doing to find a source of the necessary products to ensure that their menstruating bodies do not appear as such. And the burden of masking their menstruation becomes a double one as menstrual etiquette dictates that menstruation cannot be mentioned: adding to Burrows and Johnson's (2005) finding that British schoolgirls do not report broken dispensers because they are too embarrassed, Eliza sums up the apparent pointlessness of challenging the neglect of facilities designed to facilitate women's equal inclusion in public space because, "nobody would care about tampons."

One participant also considered the impact of this neglect on transgender men who menstruate:

"I also find it odd that they don't put tampon machines in men's bathrooms [...]. Like, you're a man and you're in a bathroom and you get your period - I can imagine that would be even more shameful".

She went on to speak positively about gender neutral toilets (GNTs) as a means of not only providing non-stigmatising access to menstrual products/disposal for trans people but also providing a counter-narrative to the silence of school-based education:

\footnotetext{
4 'Sanitary products' is the commonly used term for the items used to manage menstruation (usually disposable towels and tampons). However, we choose to reject this in favour of 'menstrual products' to avoid the notion of menstruation as unsanitary.
} 
"I think gender neutral toilets are great because they're progressive and all and also, that's where the period chat is gonna happen and men can hear it and it won't be such a big issue and, if it is, well, they can get out of that bathroom" (Tess).

Menstruation's social invisibility becomes a basis for both infrastructural neglect and shame and embarrassment: together they combine to enact forms of 'subtle sexism' (Moore 2002), but one that marginalises not only women but anyone with a body that 'leaks.'

In addition to failing to provide menstrual products, schools and workplaces are often insensitive to the fact that controlling menstruation involves more frequent trips to the toilet.

"There were times when teachers were like, 'No, no. You can't go to the toilet' but I was like, 'I really need the toilet' and you don't want to say why" (Evangeline).

"At my work... you can't just go to the toilet... you have to be like, 'Oh, I'm gonna go to the toilet. Is that ok?'... if you're going more than once a shift... it's kinda like, 'Why are you going so much?' and then obviously you don't want to be, like, declaring why you have to go" (Megan).

As Young (2005, p. 115) states, in public institutions there are 'a particular set of norms held as the standard against which all individuals should be measured', and frequently using the toilet (be that for menstruation or other needs, such as pregnancy or incontinence) falls outside that standard. But, critically, these women not only need to use the toilet more frequently around menstruation and have to ask permission from authority figures to do so but they are too ashamed to admit to menstruating in order to receive the necessary permissions. This creates a double burden whereby the imperative to privatise menstruation actually becomes a barrier to meeting the demands of that very privatisation.

Just as the body socially dys-appears in asking to use the toilet but being too ashamed to admit why, the body dys-appears physiologically in menstruation through the experience of pain. Pain is something to be managed, as Megan notes:

"I remember one time I was at work and I felt... so ill but I didn't want to [...] ask to go home sick so I just, like, put on a brave face."

This mirrors results from Brantelid et al. (2014) where women described feeling that menstruation should not interfere with their activities. However, as with needing to use the toilet more frequently, the experience of menstrual pain was social as well as physiological, with its sociality defined by its secrecy:

"A lot of women wouldn't say to their boss, 'Look, I just happen to have a really bad period this month - I need to take to take a day off'... they'd be more comfortable saying, 'Look, I have knee problems, like, I need a day off'" (Katie).

As Bordo (1995, p. 206) notes, women face increased pressure to control their 'bodily spontaneities' in the public (male) sphere and admitting to menstrual pain denotes lack of bodily control not encoded by an injured knee. The pain of menstruation must remain hidden, either through using painkillers to block pain - something most participants 
regularly did (see also Oxley, 1998) - or discursively disappearing menstruation through continuing to perform social roles despite the pain to manage shame and perceptions of lack of bodily discipline and fitness for the public sphere.

Thus, menstruation requires management. It requires the management of pain and bodily sensation, and of relationships such that menstrual etiquette can be maintained. It also entails managing a symbolically potent substance: blood. Consistent with Martin (1989), Oxley (1998) and Brantelid et al. (2014), menstrual blood was described as "yucky", "so gross!" and "not pleasant." This resulted in choices of menstrual products being underpinned by notions of cleanliness:

Jasmine: "The pad can be quite messy."

Evangeline: "Yeah, that's the thing with pads. Like, with tampons you feel a bit cleaner... because you're not sitting in blood."

Tampons contain menstrual blood within the body; however, with pads, blood is still free to traverse bodily boundaries, becoming 'matter out of place' (Douglas, 1966, p. 36) and, therefore, polluting. This appraisal of tampons as 'cleaner' is mirrored in the findings of both Oxley (1998) and Martin (1989).

However, Louisa explained that when she was "out and about" she favoured pads as when using tampons, "it's a little bit more messy to deal with the application" and Zoe reflected that:

"If you have bloody hands, you don't want to be walking out of a public bathroom to the sink, and that's why I use pads most of the time."

Whether tampon or pad, the way these women articulated their preferences was through the language of dirt, and an aversion to blood - be that be 'sitting in [it]' or walking through semi-public spaces with it on your hands (See also Greed, this volume, and Quint, this volume, on constructions of menstrual blood as dirty). While menstrual products allow women, albeit in different ways, to feel clean and to manage the dirt of menstruation, those very products, even in an unopened state, nonetheless embody the dirt they will soon absorb. This means, as Steph notes, that they must be concealed because they are "associated with something disgusting". As Jasmine explained:

"If I'm going to the toilet in the library I'm like, 'Ooh, put them in my back pocket so no one will see it.'”

Not only does menstrual etiquette demand that menstruation is hidden from view, but also that the technologies that facilitate this themselves remain hidden. Moreover, this hiding particularly when the infrastructure to facilitate this hiddenness in the public sphere is not maintained - is not always straightforward, and can entail carrying bloodied menstrual products close to one's body to protect the sensibilities of others:

“They don't have those bins or it's full, like, 'What am I supposed to do with this?' So, you have to put it in your bag, cover it with a tonne of toilet paper... then discretely find a bin" (Marie). 
Jackson and Falmagne (2013) also draw attention to this need for secrecy when disposing of menstrual products. Empty dispensers compel women to immediately stop what they are doing to find a shop which sells them. A lack of bins, or bins so full they cannot take one more item, compel women to wrap disposable menstrual products in toilet paper and carry them in pockets or bags. All the while, women need to maintain absolute secrecy and absolute hiddenness to manage the shame of even needing this equalising infrastructure. All of this points to what Moore calls 'subtle sexism' (2002) and what we see as the double burden of menstrual etiquette. Women must work hard to enter and maintain an equal position in public spaces, made harder when the facilities designed to promote women's inclusion are neglected. This reminds women that their right to these spaces is not equal - it is predicated on (unreliable) infrastructural support to facilitate their masking of menstruation from others.

In light of the emphasis on masking menstruation from men, it is striking that these women also expressed concerns about concealing it from other women in semi-public toilets. Louisa explains:

"I feel with all the technology these days they would have worked out how to make a pad that doesn't rustle!... I wait for the person next to me to flush the toilet."

Lily also explained how she opened pads "against [her] so the sound is quieter" and Zoe would "wait until the air-dryer came on." Such is the emphasis on concealment that women mask the audible evidence of their menstruation even from other women, and often do so by waiting. In addition to time taken to find a shop when dispensers are empty and time taken to find another receptacle when bins are full, women sit on toilet seats waiting for external sounds to hide the recognisable noise of disposable menstrual products being opened.

Foucault argues that with disciplinary power people internalise social norms and individually assume responsibility for conforming to them, leaving them in 'a state of conscious and permanent visibility that assures the automatic functioning of power' (1977, p. 201). These women had so internalised the need for concealment that they did it even in spaces where "everyone in there has probably had a period" (Caitlin).

However, self-regulation comes out most strongly in relation to fears of leaking. Supporting the findings of Jackson and Falmagne (2013), Brantelid et al. (2014) and others, participants spoke of making sure they always carried menstrual products "just in case" and Megan even explained:

"There's been times when I haven't started but l've maybe put on a pad in the morning 'cause I know it's gonna come soon... you don't want to be caught out in that situation".

Others spoke of wearing "double" menstrual products (i.e. a pad and a tampon) to be "safe" and, even then, constant vigilance is required:

"I feel self-conscious about, you know, if I'm leaking or anything. I need to go to the bathroom a lot more just to, like, check it" (Evangeline). 
Women may need to go to the toilet more frequently in response to a need to urinate more often, and to change menstrual products when necessary, but also as part of an on-going process of self-surveillance: women must 'watch themselves' (Ginsburg, 1996, p. 373) to conceal a process which emphasises their difference to men and has historically justified their exclusion from public life.

The strength of the disciplinary expectations of menstrual etiquette was best highlighted in participants' accounts of breaching it.

"This morning I thought my period had started and I was panicking. I was getting cold sweats and I was walking to one of my lectures... I ran to the toilet but it was fine... but I still panicked" (Lily).

"I was heading into town [...] and 10/15 minutes in I felt something and was like, 'Oh no', popped into the nearest place... I had a stain this big and it would have been so obvious to people driving by. I was like, 'Oh my god, this is so embarrassing' [...] I called my mum and was like... 'I need you to come here and bring trackies [track suit bottoms]'" (Tess).

This suggests that the idea 'public' bodies do not menstruate is firmly entrenched, evidenced in the embarrassment of failing to conceal menstruation, the imperative to rectify this, and the fear of others witnessing the transgression.

Menstrual products and constant vigilance are required to enact menstrual etiquette. However, as evidenced above, even when taking these measures, efforts can fail. Therefore, participants described using additional technologies to optimise control and concealment. Some used diaries and menstrual tracking apps to help predict their periods. For example, Nina "put a marker in [her] phone [...] for the comfort of knowing [...] next month when to expect it" and Ruby used an app, explaining, "It's great... It gives you a notification being like, 'Two days until your period!'” These women experienced understanding the timing of menstruation as essential to controlling it, necessary to succeed in the 'male world' of the public sphere (Bordo, 1995, p. 209). However, the most commonly cited means of fully controlling and, therefore, privatising menstruation, as for Granzow (2007), was the use of oral contraceptives.

"I use the pill to regulate... I just love knowing that my period will come on a Wednesday afternoon and it will last for, like, three days" (Evangeline).

"When I first started going on the pill it was because I didn't want to get my period at, like, random times... I just felt a lot more in charge of my body when I got it" (Marie).

However positively individual women described these technologies, Bordo reminds us that 'one's own feelings of personal comfort and power do not mean that one is not servicing an oppressive system' (1995, p. 31). Individual acts which reduce (anxiety about) potential breaches of menstrual etiquette may be beneficial for the individual in the moment, but simultaneously work to uphold a patriarchal social structure in which menstruation must continue to be concealed. In this case, women go as far as to alter the hormonal balance of 
their bodies to meet the expectation that the female body must be rigorously controlled before it is rendered acceptable in the public sphere of 'Rational Man' (Longhurst, 2001), sustaining the privileging of the mind over the body and the masculine over the feminine.

But increasingly menstruation is not being concealed. Concealment norms create a 'disciplinary burden' for women (Young, 2005, p. 112) and mark out inequality between men and women at a time when women have formal equality in the Western public sphere (Laws, 1990). Yet, as Foucault reminds us, 'there are no relations of power without resistances' (1980, p. 141). Despite all participants conforming to the demands of menstrual etiquette, opposition was also shown.

This began with praising women who challenged concealment norms. For example, after explaining how she took efforts to disguise the noise of opening disposable pads in public toilets, Louisa went on to say:

"If I ever hear another person, like, rustling a packet I'm always like, 'You go girl you rustle that packet!'”

While still concealing the rustling in her own practice, Louisa internally or externally celebrated the refusal to do so in others. Similarly, when discussing photographs of Kiran Gandhi 'free-bleeding' in the 2015 London Marathon (Gandhi, 2015), participants in every focus group stated that, although they could not do what she did, they thought she was "brave" and Lily questioned the affective experience of embarrassment:

"This one time [...] I had to ask my friend... 'Do you have any pads or anything?' and I got really embarrassed [...] and I was thinking... 'why was I embarrassed?'... and if I'm sitting in the library and want to change my pad... I try my best to, like, hide it in my pocket... but why am I trying to hide it?"

Like Louisa and her rustling packet and the women's responses to 'free-bleeding', Lily conformed to the status quo but was also beginning to question it and some had begun to change their practice. Both Harriet and Megan reflected on no longer hiding menstrual products:

"I feel like I did that and I don't anymore but I've kind of made myself not do that anymore in a way" (Harriet).

“I think I used to but now I always try to be like, 'Fuck this, I'm gonna do it!' But it's taken me years to get to this stage" (Megan).

Not hiding evidence of menstruation required deliberate thought and considerable effort. While resistance is possible, it is hard, and this difficulty highlights the power of the norms of menstrual etiquette - that female bodies, and menstruation, should be privatised.

A step on the way towards resisting menstrual etiquette in practice was resisting it discursively, first through talking openly with other women: 
"I get quite a lot of comfort from talking to, like, your friends... there's something so nice in chatting to someone about things and you're like... we're all the same" (Caitlin).

"It's a universal experience as far as women go... I think the biggest take-away from this whole focus group for me is that there is a lot of solidarity in having your period" (Marie).

As Martin (1989) highlights, managing menstruation establishes a common identity and connection between women. The same sentiment has been found more recently, with Brantelid et al. (2014, p. 606) referencing a supportive 'female community' between all who have experienced menstruation. Fostering spaces of dialogue could be an early way to counteract the effects of the disciplinary power of menstrual etiquette which leaves 'each actor [...] alone, perfectly individualised' (Foucault, 1977, p. 199).

\section{Conclusion}

This chapter has explored how students at a Scottish university enact, embody, and critique menstrual etiquette. However, we have also exposed the way in which menstrual etiquette in contemporary Scottish society entails a double burden. Not only must women work to mask menstruation both discursively and practically to maintain the invisibility central to Laws' (1990) conception of menstrual etiquette, but the social and material infrastructure to enable them to do this is often inadequate. As such, women are required to work around these infrastructural oversights by walking long distances to find menstrual products when dispensers are un-stocked, carrying bloodied tampons and pads when bins are too full, consuming painkillers or continuing to work while in pain to avoid the shame of disclosing their menstruating status, and even altering the hormonal balance of their bodies to render menstruation predictable and, thus, reducing the anxiety attached to it. However, the anxiety that remains, over leaking or, where oral contraceptives are not used, over unexpectedly starting menstruation, require self-surveillance but also take time: time to repeatedly visit the toilet to check for signs of staining and time spent processing feelings of shame and embarrassment when breaches of menstrual etiquette do occur. In short, the social and infrastructural neglect of menstruation is directly linked to its status as bodily, female and belonging 'behind the scenes of social life' (van Krieken, 1998, p. 96). This status means it is not actively discussed and rarely raised by women as a source of discomfort - for to raise infrastructural inadequacy is in itself a breach of the silence required of menstrual etiquette. Examining menstrual etiquette and its implications, thus, starkly reveals how women continue to face symbolic and material exclusion from the public sphere.

However, while the expectation to conceal all evidence of menstruation is pervasive, some women are beginning to challenge it: through publicly free-bleeding (as Gandhi did in the 2015 London marathon) or explaining poor sporting performance as a result of menstruation (as swimmer Fu Yuanhui did in the 2016 Olympics) high profile figures bring into question why menstruation cannot speak its name or show its colours (Gandhi, 2015; Phillips, 2016). As the women discussed here indicated, whether in thought or deed, rustling 
wrappers and even just talking about menstruation as common experience are beginning to chip away at menstrual etiquette as we know it. As a result, we make the following recommendations:

- In school-based education, menstruation should be addressed with young people of all genders present, not only to break the silence around menstruation as a legitimate topic for discussion in front of males, but to facilitate inclusion of noncisgender young people in understanding bodily change at puberty (see Quint, this volume, for suggestions to make menstrual education gender-inclusive).

- The provision - and maintenance - of menstrual products and dispensers in public toilets should be prioritised as much as toilet paper. The appropriate bins for the disposal of these products should be provided and emptied regularly and be made available in all toilets, regardless of gender.

- Menstruation should be acknowledged in work and educational settings. Employers and educators should ensure menstrual management technologies are adequately maintained and accept that, once a month, female-bodied staff will menstruate and may experience discomfort that they are too embarrassed to name as menstrual pain.

- Since data collection, Monica Lennon (MSP) has spearheaded a campaign to make menstrual products freely available in Scotland - as well as proposing that schools, colleges, and universities supply their toilets with these products - and a six-month pilot of providing free menstrual products to low-income women in Aberdeen began in September, 2017 (McCourt, 2017). This has now been rolled out to educational establishments nationally and this should be fully and sensitively evaluated.

Together, these changes can operate in a 'virtuous circle' as each shift positively reinforces and makes the next easier to undertake.

\section{Limitations and Directions for Future Research}

These findings address female students' experiences of menstrual etiquette and the work they do manage the double burden of menstrual etiquette. These women were young (aged 19-32), and the oldest among them stated that some of her self-consciousness had lessened with age and others explained challenging concealment norms they had been unable to when younger. Further, these women were all university educated. Thus, there is a need to build on the work here to explore how women's views and experiences vary by age (and change across the life course) as well as how they vary by class, employment type and (given the study's focus on a single Scottish university) region.

Managing bodily exuviae has long been noted as a site of distinction, and this has been addressed particularly in relation to urination and defecation (see, for example, Inglis, 2000; Stallybrass \& White, 1986). However, when the precariously employed women in these focus groups describe having to ask permission to use the toilet at work, they point to an important but under-explored issue: the intersection of class and gender with regards to menstrual management. These women experienced the heightened surveillance that often 
goes along with precarious and low-status forms of work which made it difficult to meet the contradictory demands of menstrual etiquette - controlling menstruation through more frequent toilet trips but not revealing the purpose of these trips to superiors. This classed barrier to effective menstrual management is linked to a phenomenon which has recently made the UK headlines: period poverty. Many women and girls living on the breadline simply cannot afford menstrual products, being forced to stuff their underwear with toilet paper and even miss school (Brewer, 2017; Bulman, 2017). Work is being done to supply homeless and other marginal women with menstrual products (Pickering \& Wiseman, 2015), to provide all schoolgirls with access to menstrual products in schools (Lawless, 2018), and to abolish the 5\% VAT currently attached to menstrual products (Coryton, 2018). However, further scholarly engagement, particularly into how the twin dimensions of period poverty in its material forms and class-based surveillance doubly disadvantage already disadvantaged women in performing adequate menstrual etiquette is required.

Going further still, period poverty is by no means a phenomenon restricted to disadvantaged women in the UK. There is an emerging body of work on women's experiences of menstruation in low and middle-income countries, where women can lack access to menstrual products or toilets of any description. Work has begun to be published on the impact of menstruation on girls' education and personal safety, as well as the ecological consequences of disposable menstrual products, but there is much more to be done.

A final, important, limitation of this research is that by recruiting participants who both had experience of menstruating and self-identified as women it only focuses on the experiences of cisgender women. Menstruation is highly symbolic of femaleness and ties bodies, practice and social spheres together. In the recent rise of transgender rights in public discourse and concomitant discussion of gendering public toilets, menstruation has remained largely invisible. This is beginning to change: Cavanagh (2010) addresses men's menstruation in public toilets; Chrisler et al. (2016) draw attention to 'Queer periods'; and trans artists, such as Cass Clemmer, are using art and social media to highlight that 'periods are not just for women' (Beresford, 2017). These are welcome developments, but further research in these areas in particular, and menstrual etiquette in general, are needed to continue to expose, understand and challenge the everyday sexism of menstruating in public.

\section{$\underline{\text { References Cited }}$}

Beard, M. (2017). Women and Power. London: Profile Books.

Beresford, M. (2017, July 24). This trans non-binary artist is making art with their menstrual blood. Pink News. Retrieved from https://www. pinknews.co.uk/2017/07/24/this-trans-nonbinary-artist-is-making-art-with-their-menstrual-blood/ 
Bordo, S. (1995). Unbearable Weight: Feminism, Western Culture, and the Body. California: University of California Press.

Brantelid, I. E., Nilver, H., \& Alehagen, S. (2014). Menstruation During a Lifespan: A Qualitative Study of Women's Experiences. Health Care for Women International. 35, 600616.

Brewer, K. (2017, August 9). How Scotland is putting a stop to period poverty. The Guardian. Retrieved from https://www.theguardian.com/society/2017/aug/09/scotland-stop-periodpoverty-food-banks

Bryman, A. (2012). Social Research Methods. New York: Oxford University Press Inc.

Buckley, T. \& Gottlieb, A. (1988). A Critical Appraisal of Theories of Menstrual Symbolism. In T. Buckley \& A. Gottleib (Eds.), Blood Magic: The Anthropology of Menstruation (pp. 3-50). California: University of California Press.

Bulman, M. (2017, March 14). Girls from low-income families skipping school during periods because they can't afford sanitary products. Retrieved from https://www.independent.co.uk/news/uk/home-news/girls-skipping-school-periods-cantafford-tampons-sanitary-pads-a7629766.html

Burrows, A. \& Johnson, S. (2005). Girls' experiences of menarche and menstruation. Journal of Reproductive and Infant Psychology. 23, 235-249.

Cavanagh, S. L. (2010). Queering Bathrooms: Gender, Sexuality, and the Hygienic Imagination. USA: University of Toronto Press.

Choi, P. Y. L. \&McKeown, S. (1997). What are Young Undergraduate Women's Experiences of the Menstrual Cycle? International Journal of Obstetrics and Gynaecology. 18, 259-65.

Coryton, L. (2018). Stop taxing periods. Period. \#EndTamponTax [Petition].Retrieved from https://www.change.org/p/george-osborne-stop-taxing-periods-period

Chrisler, J. C., Gorman, J. A., Manion, J., Murgo, M., Barney, A, Adams-Clark, A., Newton, J. R., \& McGrath, M. (2016). Queer periods: attitudes toward and experiences with menstruation in the masculine of centre and transgender community. Culture, Health $\&$ Sexuality. 18, 1238-1250

Douglas, M. (1966). Purity and Danger: An analysis of the concepts of pollution and taboo. London: Routledge.

Edinburgh City Council. (2017). Public Toilets. Edinburgh City Council. Retrieved from https://www.edinburgh.gov.uk/directory/61/public toilets 
Elias, N. (1978). The Civilizing Process. Hoboken, NJ: Wiley-Blackwell.

Foucault, M. (1977). Discipline and Punish: The Birth of the Prison. London: Penguin Books Ltd.

Foucault, M. (1980). Power/Knowledge: Selected Interviews and Other Writings 1972-1977. Hertfordshire: The Harvester Press Ltd.

Gandhi, K. (2015, August 14). Here's why I ran the London Marathon on the first day of my period - and chose not to wear a tampon. The Independent. Retrieved from https://www.independent.co.uk/voices/comment/heres-why-i-ran-the-london-marathonon-the-first-day-of-my-period-and-chose-not-to-wear-a-tampon-10455176.html

Ginsburg, R. (1996). Don't tell dear: The material culture of tampons and napkins. Journal of Material Culture. 1, 365-375.

Granzow, K. (2007). De-Constructing 'Choice': The Social Imperative and Women's Use of the Birth Control Pill. Culture, Health and Sexuality. 9, 43-54.

Greed, C. (2016). Taking women's bodily functions into account in urban planning and policy. Town Planning Review. 87, 505-524.

Greed, C. (2019). Join the Queue: Including Women's Toilet Needs in Public Space. The Sociological Review. X, 217-253.

Grosz, E. (1994). Volatile Bodies: Toward a Corporeal Feminism. Bloomington: Indiana University Press.

Inglis, D. (2001). A Sociological History of Excretory Experience: Defacatory Manners and Toiletary Technology. Lampeter: Edwin Mellen Press.

Irigaray, L. (1985). This sex which is not one. New York: Cornell University Press.

Jackson, T. \& Falmagne, R. J. (2013). Women wearing white: Discourses of menstruation and the experience of menarche. Feminism \& Psychology. 23, 379-398.

Johnston-Robeldo, I. \& Chrisler, J. C. (2013). The Menstrual Mark: Menstruation as Social Stigma. Sex Roles, 68, 9-18.

Johnston-Robeldo, I., Ball, M., Lauta, K. \& Zekoll, A. (2008). To Bleed or Not to Bleed: Young Women's Attitudes Toward Menstrual Suppression. Women \& Health. 38, 59-75.

Kissling, E. A. (1996). Bleeding Out Loud: Communication about Menstruation. Feminism \& Psychology. 6, 481-504. 
Kissling, E. A. (2013). Pills, Periods, and Postfeminism. Feminist Media Studies. 13, 490-504

Kitzinger, J. (1994). The methodology of focus groups: The importance of interaction between research participants. Sociology of Health and IIIness. 16, 103-121.

Kristeva, J. (1982). Powers of Horror: An Essay on Abjection. New York: Columbia University Press.

Lawless, H. (2018). Provide free sanitary products in UK schools! \#PeriodPotential [Petition].Retrieved from https://www.change.org/p/provide-free-sanitary-products-in-ukschools-periodpotential

Laws, S. (1990). Issues of Blood: The Politics of Menstruation. Hampshire: The Macmillan Press Ltd.

Lea, R. (2001). The Performance of Control and the Control of Performance: Towards an Anthropology of Defecation. (Doctoral Thesis, Brunel University). Retrieved from http://bura.brunel.ac.uk/handle/2438/6376)

Leder, D. (1990). The Absent Body. Chicago: University of Chicago Press.

Letherby, G. (2003). Feminist Research in Theory and Practice. Buckingham: Open University Press.

Longhurst, R. (2001). Bodies: Exploring fluid boundaries. London: Routledge.

Madriz, M. (2000). Focus Group in Feminist Research. In N. K. Denzin \& Y. S. Lincoln (Eds.), Handbook of Qualitative Research (pp. 835-850). Thousand Oaks, CA: Sage.

Mamo, L. \& Fosket, J. R. (2009). Scripting the Body: Pharmaceuticals and the (Re)Making of Menstruation. Journal of Women in Culture and Society. 34, 925-949.

Martin, E. (1989). The Woman in the Body. Milton Keynes: Open University Press.

McCourt, S. (2017, August 15). Labour MSP Monica Lennon launches period poverty consultation. The Daily Record. Retrieved from https://www.dailyrecord.co.uk/news/localnews/labour-msp-monica-lennon-launches-10992625

Moore, S. A. (2002). Facility hostility? Sex discrimination and women's restrooms in the workplace. Georgia Law Review. 36, 599-634.

Newton, V. L. (2012). Status passage, stigma and menstrual management: 'Starting' and 'being on'. Social Theory \& Health. 10, 392-407.

Newton, V. L. (2016). Everyday Discourses of Menstruation: Cultural and Social Perspectives. London: Springer. 
Paterson, K \& Hughes, B. (1999). Disability Studies and Phenomenology: The Carnal Politics of Everyday Life. Disability and Society. 14, 597-610.

Phillips, T. (2016, August 16). 'It's because I had my period': swimmer Fu Yuanhui praised for breaking taboo. The Guardian. Retrieved from https://www.theguardian.com/sport/2016/aug/16/chinese-swimmer-fu-yuanhui-praisedfor-breaking-periods-taboo

Pickering, L, Neale, J and Nettleton, S. (2013). Recovering a Fecal Habitus: Analysing Heroin Users' Toilet Talk. Medical Anthropology Quarterly. 32, 95-108.

Pickering, L. \& Wiseman, P. (2015). Do Refugees have Periods? Sociology's Campaign to Provide Sanitary Products to Calais' Refugees [Blogpost]. Retrieved from https://www.glasgowsociology.com/reflections-on-research/refugees-and-migration/dorefugees-have-periods-sociologys-campaign-to-provide-sanitary-products-to-calaisrefugees/

Quint, C. (2019). From embodied shame to reclaiming the stain: reflections on a career in menstrual activism. The Sociological Review. X, 217-253.

Research \& Forecasts Inc. (1981). The Tampax Report: Summary of Survey Results on a Study about Attitudes towards Menstruation. New York: Research and Forecasts.

Seale, C. (1999). The Quality of Qualitative Research. London: Sage.

Shildrick, M. \& Price, J. (1999). Opening on the Body: A Critical Introduction. In J. Price and M. Shildrick (Eds.), Feminist Theory and the Body: A Reader (pp. 1-15). Edinburgh: Edinburgh University Press.

Shilling, C. (2003). The Body and Social Theory. London: Sage.

Skeggs, B. (1994). Situating the production of feminist ethnography. In M. Maynard \& J. Purvis (Eds.), Researching Women's Lives from a Feminist Perspective (pp. 72-92). London: Taylor \& Francis.

Smith, L. W. (2011). The Body Embarrassed: Rethinking the Leaky Male Body in Eighteenth Century England and France. Gender and History. 23, 26-46.

Stallybrass, P. \& White, A. (1986). The Politics and Poetics of Transgression. Ithaca: Cornell University Press.

van Krieken, R. (1998). Norbert Elias. London: Routledge.

Williams, L. R. (1983). Beliefs and Attitudes of Young Girls Regarding Menstruation. In S. Golub (Ed.), Menarche (pp. 139-148). Lexington, MA: Lexington Books. 
Young, I. M. (2005). On Female Body Experience: "Throwing Like a Girl" and Other Essays. Oxford: Oxford University Press. 